\title{
Design sem desenho: a importância relativa do desenho em processos de design
}

\author{
Design without drawing: the relative \\ importance of drawing in design methods
}

\begin{abstract}
Airton Cattani
Arquiteto, Professor Titular do Curso de Design e do Programa de Pós-Graduação em Design da UFRGS, Porto Alegre, Brasil. aacc@ufrgs.br
\end{abstract}

\section{Mariana de Oliveira do Couto e Silva}

Designer, Mestranda do Programa de Pós-Graduação em Design, UFRGS, Porto Alegre, Brasil. marianacoutoesilva@gmail.com
RESUMO:

O desenho é uma ferramenta de representação hegemônica no design, cumprindo um papel fundamental nos processos de projeto, na comunicação e na fabricação de bens de consumo. No entanto, alguns processos de projeto e fabricação podem eventualmente relativizar a importância do desenho como instância de antecipação, tendo em vista as peculiaridades do processo criativo ou produtivo adotado por designers ou fabricantes. Por meio de estudos de caso, este artigo aborda algumas situações em que o desenho não exerce um papel protagonista no processo de projeto ou produção em design. Para tanto, foram elencadas quatro áreas do design e, por meio de análises de casos específicos, buscou-se investigar o uso do desenho como ferramenta de importância relativa em alguns processos criativos/ produtivos. Os resultados indicam que, em que pese a importância do desenho em processos de projeto e produção em design, eventualmente este papel pode ser relativizado em função das peculiaridades das áreas e dos processos adotados.

Palavras-chave: desenho de design, design autoral, processos criativos.

\section{ABSTRACT:}

Drawing is a hegemonic graphic resource in design, playing a fundamental role in project methods, in communication and in the manufacture of consumer goods. However, some design and manufacturing methods may eventually reduce the importance of drawing as an anticipation tool, given the peculiarities of the creative or productive process. Through case studies, this article shows some cases that makes drawing's role relative in design or production methods. For this, four areas of design were listed and, through specific cases, the use of drawing as a tool of relative importance in design methods was investigated. The results point out that, despite the relevance of drawing in the design and production process, eventually this role can be relativized according to the peculiarities of the areas and design methods.

Keywords: design drawing, author design, creative processes. 


\section{INTRODUÇÃO}

Enquanto campo de conhecimento que trabalha com a antecipação de uma realidade, propondo uma organização para a matéria que dará origem a produtos, projetos em design costumam incorporar em seus processos etapas onde a existência de algo é registrada antecipadamente, de modo que se possa decidir sobre aspectos técnicos, estéticos, formais ou fabris do produto final. É o desenho, em suas várias modalidades - técnico, artístico, de observação, realista ou abstrato, projetivo ou especulativo -, a ferramenta que melhor responde a estes requisitos antecipatórios.

0 desenho de design - e por analogia, de todas as áreas que tratam da representação de objetos fabricados - é uma elaborada abstração desenvolvida pela espécie humana ao longo dos séculos, pois para definir os limites dos objetos representados emprega um elemento que não existe na natureza: a linha. A rigor, a variação que é possível perceber entre uma face e outra de um objeto constituído de um mesmo material é apenas de luminosidade e de mudança de plano físico, não existindo nenhuma linha definidora dos limites das superfícies. Mesmo em um objeto composto por vários materiais, seus limites são definidos pelo término dos próprios materiais e nunca por linhas com existência real. É a capacidade de abstração e as convenções adotadas no registro gráfico que possibilitam que o olho humano identifique uma linha como um limite de uma superfície, permitindo assim representar objetos empregando linhas de várias espessuras, sombras, texturas, indicações textuais e uma série de outras convenções que procuram contornar a dificuldade de representar um objeto tridimensional em um suporte bidimensional e proporcionar acesso à sua inteligibilidade (FRUTIGER, 1999, DONDIS, 2007).

São as convenções que nos permitem entender um objeto por sua representação, onde estão envolvidos dois requisitos: o que vemos e o que sabemos sobre o objeto. Somente entendemos que a Figura 1 representa um sólido porque o conhecemos previamente e sabemos quais são suas características espaciais e formais. Parafraseando René Magritte, ${ }^{1}$ isto não é um sólido, mas uma imagem que nos remete a ele, pois o conhecemos como objeto físico, entendemos suas peculiaridades e compreendemos que estas linhas nos proporcionam a sensação visual de estar vendo um sólido.

\footnotetext{
1 Autor da obra "A traição das imagens - Isto não é um cachimbo (La trahison des images - Ceci c'est ne pas une pipe - 1928-29), que pode ser vista em http://collections.lacma.org/node/239578. Neste tela, Magritte representa um cachimbo acompanhado da afirmação de que aquilo não é um cachimbo, colocando em evidência a distância entre imagem e realidade. Acesso: 19/03/2020.
} 
Figura 1 - Um sólido representado em perspectiva por suas superfícies definidas por diferentes sombreamentos (esq.) e por linhas (dir.).
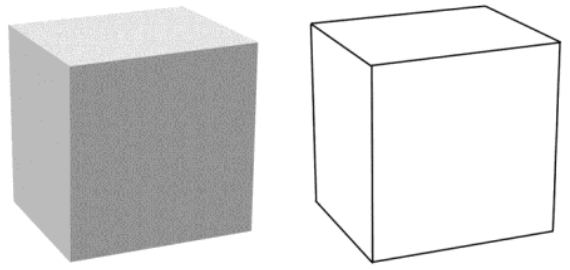

Fonte: elaborado pelo autor.

0 fato de o desenho ser registrado em superfícies bidimensionais faz com que a tridimensionalidade inerente aos objetos representados tenha que ser inferida pelo observador. Assim, será a cognição e a própria experiência vivida que nos permitirão entender um conjunto de linhas ou superfícies como representantes de um objeto.

Meio de comunicação por excelência e parte de um sistema de representação em design (CATTANI; LEENHARDT, 2017), as várias modalidades de desenho empregadas no design permitem antever o produto sem que sua forma esteja condicionada ou limitada pelas eventuais restrições impostas pela realidade, proporcionando condições para dar vazão à criatividade, à invenção e à inovação. Configurando-se na esteira de conhecimentos desenvolvidos pela representação em arquitetura e engenharia (CATTANI, 2020), os vários tipos de desenho utilizados no design empregam tanto o sistema projetivo triédrico regulado por normas técnicas, quanto desenhos livres, sempre adaptados às particularidades e escalas dos objetos projetados. Em etapas de fabricação do produto, o desenho também mostra sua importância, contribuindo na organização dos processos produtivos que conduzirão à materialização do artefato, bem como na sua documentação, que se configura como importante aspecto do processo produtivo, seja de peças únicas ou produzidas em pequena ou larga escala. A documentação deve ser considerada não somente no sentido da reprodução de uma peça específica, mas também no sentido do registro da mesma (para a posteridade), além de atender aspectos legais (por exemplo, em patentes e questões envolvendo direitos autorais).

Com as técnicas informatizadas em uso a partir do final do século XX, os sistemas de representação adquiriram nova agilidade, graças à capacidade de apresentar de modo quase imediato as principais características dos projetos. Atributos como rapidez, fidelidade, exatidão, correção, visualizações simultâneas de diversos pontos de vista em tempo real e capacidade de simulação muito próxima da realidade aparente são associados a este novo contexto tecnológico que, no entanto, nada mais faz do que utilizar os sistemas de representação desenvolvidos ao longo da história como, por exemplo, as 
projeções ortográficas, apresentando-os em uma nova interface de forma mais ágil e rápida.

\section{OBJETIVOS}

Este conjunto favorável de atributos tornaria o desenho - sobretudo o desenho técnico projetivo, que segue regras e diretrizes rigorosas de modo a ter uma interpretação unívoca - aparentemente imprescindível nos processos que levam à fabricação de produtos intermediados pelo design. No entanto, é possível localizar situações específicas onde o desenho tem uma importância relativa, podendo até mesmo ser dispensado. Mesmo em um contexto de tecnologia crescente e onipresente, em nichos específicos do design é possível localizar situações onde o desenho desempenha um papel restrito, podendo ter seu uso e importância reduzidos em função das especificidades de alguns processos de projeto ou fabricação. Assim, o objetivo deste artigo é localizar e analisar algumas práticas profissionais em design nas quais o desenho desempenhe uma função relativa.

Metodologicamente, foram elencadas quatro áreas específicas do design, de modo a tornar viável um estudo de caso: moda e vestuário, cerâmica, artesanato e mobiliário. A partir desta delimitação, foram investigadas situações específicas em que a representação por meio dos vários tipos de desenho desempenha um papel de importância relativa, principalmente se comparado com outras áreas ou processos produtivos, notadamente aqueles de produção em larga escala, onde o protagonismo do desenho é inquestionável e praticamente insubstituível. A investigação foi levada a efeito por meio de entrevistas pessoais com profissionais e observação de processos de trabalho documentados em sites, com atenção especial àqueles envolvendo o desenho, comparando com referências bibliográficas da área. Sendo um estudo sobre situações localizadas, seus resultados dizem respeito a nichos de específicos de determinados autores ou processos, e não são generalizáveis. Estes exemplos não procuram diminuir a importância do desenho nas várias etapas do desenvolvimento de um produto, mas apontar possibilidades, tanto criativas quanto relativas à produção em escala individual ou em série, em que um grau de liberdade maior pode ser exercido por parte dos autores/produtores quando não intermediado pela racionalidade representada por algumas categorias de desenho. Para este artigo, o desenho de design é entendido como todo o desenho que precede a produção do produto, seja ele técnico ou apenas um simples rabisco. 


\section{ANTECEDENTES HISTÓRICOS}

Na milenar história do desenho associado a alguma prática produtiva é possível observar uma curva variável de credibilidade e importância. Segundo Jungmann (1996), antes da Renascença o desenho era considerado uma disciplina auxiliar da pintura, julgado indigno de ser realizado por pintores de renome, sendo sistematicamente destruído após sua utilização nas etapas preparatórias da obra final. Prova disso é a relativa escassez de desenhos com estas características que chegaram até nossos dias. Por outro lado, o desenho nem sempre teve seu caráter de analogia explícita com uma realidade, com uma decodificação fácil e imediata. Os desenhos de arquitetura primitivos, por exemplo, não faziam uso de códigos gráficos nos moldes que conhecemos atualmente: sua leitura e interpretação devia fazer uso de um filtro intelectual que corrigia os supostos erros, ou seja, o aparente desacordo entre representação e realidade (SAINT-AUBIN, 2002). Além do mais, é importante salientar que a construção de uma obra era um processo que dependia em grande medida do acompanhamento in situ do projetista responsável, situação que foi gradativamente mudando em função tanto da consolidação da profissão de arquiteto - e sua consequente modificação das relações de trabalho na obra (FERRO, 1982) - quanto do aprimoramento do desenho enquanto instância antecipatória. Pela analogia que é possível traçar entre arquitetura e design, é possível afirmar que os processos produtivos anteriores à consolidação do design como campo específico, a partir da Revolução Industrial levada a cabo a partir de meados do século XIX (MIDALL, 2009), tinham como constante a presença do profissional artífice que acompanhava as várias etapas de concepção e fabricação. Esta presença fazia com que a importância do desenho pudesse ser relativizada, uma vez que o acompanhamento presencial e o saber fazer do mestre artífice davam conta das diversas etapas da produção.

Aprimorado durante séculos por estudiosos de áreas como geometria, engenharia, arquitetura, e mais recentemente design e informática, nos últimos tempos o desenho de design estaria chegando a um dos pontos altos da curva credibilidade e importância. Os novos meios de visualização intermediados pela tecnologia informática, como a visualização 3D, têm permitido reduzir a barreira da compreensão do tridimensional intermediada pelo bidimensional, tornando a percepção do que está representado mais rápida, acurada e eficiente, o que, a rigor, colocaria o desenho em um patamar de ferramenta indispensável para qualquer projeto em design contemporâneo. Porém, algumas situações específicas do processo de projeto e/ou produção adotados por determinados designers e/ou produtores colocam o desenho sobretudo o desenho técnico - em uma condição de importância relativa, eventualmente até dispensando-o. No entanto, é importante ressaltar que esta 
condição sempre estará ligada à escala produtiva ou ao processo de projeto adotado. Mesmo que algumas dessas atividades - cerâmica artesanal, por exemplo - não tenham uma tradição histórica de uso do desenho como antecipador de soluções formais, uma demanda comercial em larga escala poderia eventualmente se beneficiar deste recurso gráfico quando incorporado ao processo produtivo.

\section{ESTUDOS DE CASO}

Este brevíssimo retrospecto histórico permite retomar algumas questões importantes: o desenho é sempre fundamental para os processos de design? Todo designer desenha? Se por um lado a história e a literatura relativa ao desenho de design, juntamente com a prática profissional de inúmeros designers e suas equipes, comprovam a importância e o uso intenso deste recurso nos processos que conduzem ao produto, algumas situações específicas parecem indicar que nem sempre é assim: embora tenha papel importante nos modernos processos de concepção e produção em design, muitas vezes o desenho tem um papel restrito ou até mesmo dispensável nesses processos.

A importância do desenho está associada às características do processo de projeto, ao sistema produtivo adotado - em escalas que podem ser grandes, médias, pequenas ou de peças únicas -, ao conceito de design que é levado em conta e mesmo às características do processo criativo adotado pelo autor do projeto, além das peculiaridades do próprio objeto projetado. Entendendo o design como um processo de modificação da matéria de modo a transformá-la em produtos produzidos em quantidades variáveis, parece evidente que esta transformação deveria ser detalhadamente planejada, de modo a proporcionar otimização de materiais e processos produtivos, além de possibilitar a uniformidade - formal, cromática, dimensional, funcional - dos resultados. Nesse sentido o desenho como forma de antecipação parece ser de extrema importância, pois a partir dele se define tanto o aspecto final do produto quanto o processo produtivo que conduzirá o produto às prateleiras e locais de consumo. No entanto, quando se tem em mente que o design pode ser regido por outros conceitos não tecnicistas, que o aproximam da arte - no sentido proposto por Munari (1971) -, deixando de ser arte para a parede da sala de visitas e indo para os equipamentos de cozinha, por exemplo, associando-a à vida cotidiana, ou do próprio design de exceção (quando são produzidas peças únicas, com valor de obra em si), é possível perceber que o uso do desenho pode ser momentaneamente relativizado em prol de processos de projeto e produção peculiares e localizados em alguns nichos de trabalho. 
Outro fator a ser considerado é que a tecnologia induziu a transformação do profissional designer em um profissional multitarefa que não apenas projeta bens de consumo, mas também os produz (MARGOLIN, 2002). Para um designer que também é um produtor, o desenho acaba tendo sua importância relativizada, pois este serve como um intermediador entre a criação e a produção que, historicamente, desde a Revolução Industrial, são desempenhados por pessoas diferentes (BÜRDEK, 2006). Com o rompimento da divisão de tarefas, o desenho pode ter sua relevância diminuída. Alguns exemplos relatados a seguir demonstram isso nas áreas de moda e vestuário, cerâmica, artesanato e mobiliário.

\subsection{Design de moda e vestuário}

No design de moda e vestuário, onde o desenho tem grande importância, sobretudo no processo de fabricação industrial de peças com vistas ao aproveitamento otimizado dos materiais, o processo de criação conhecido como moulage (draping ou modelagem tridimensional diretamente sobre o manequim) pode dispensar momentaneamente o desenho, uma vez que a peça é modelada sobre um manequim especial (geralmente estofado, para receber alfinetes) ou mesmo sobre o corpo humano, permitindo visualizar a peça à medida que está sendo criada e mostrando os efeitos e caimentos do tecido ao longo do processo de modelagem (Figura 2).

Figura 2: Estilista criando peça de alta costura utilizando a técnica da moulage.

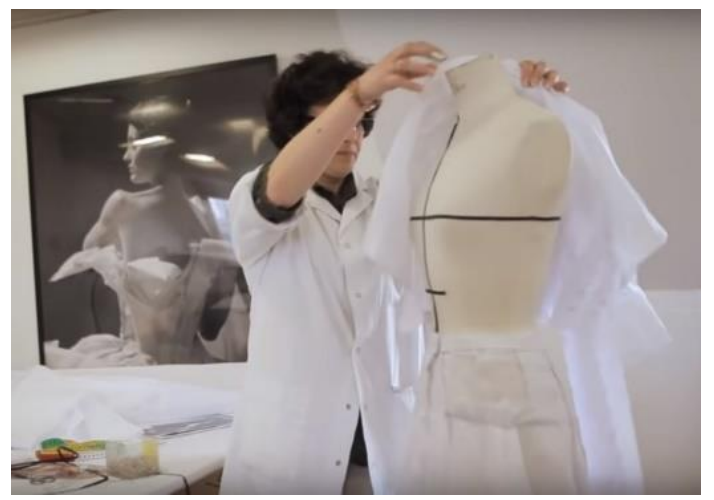

Fonte: Frame de vídeo disponível no YouTube (2020)

Assim, a moulage permite tanto efetuar a própria modelagem, em um processo criativo onde a liberdade e a experimentação desempenham um papel importante, quanto interpretar modelos já concebidos e servir de base para etapas de modelagem plana. Utilizada tanto para produção em série quanto em peças únicas criadas por casas de alta costura² ou por estilistas com produção de menor divulgação, esta técnica explora as possibilidades

2 É possível ver a utilização dessa técnica pela casa Dior em www.youtube.com/watch?v=sGULpcJKbmc ou www.youtube.com/watch?v=RAXksLhLFAA Acesso: 30/03/2020 
plástico/formais e mesmo estruturais dos tecidos que o desenho não dá conta de representar, e é utilizada quando se quer explorar alternativas que não são ainda conhecidas, quer sob o ponto de vista formal ou de comportamento do material utilizado, quer para dar vazão à criatividade, experimentação e inovação.

Testando várias possibilidades sobre o objeto concreto, a moulage permite contornar eventuais entraves relacionados à habilidade de representação por parte do projetista, bem como verificar imediatamente o resultado em termos de forma e caimento da peça em projeto. 0 trabalho diretamente sobre o tecido no manequim, sem a intermediação de alguma instância de representação, mostra-se favorável à pesquisa sobre novas possibilidades formais, cuja simulação seja relativamente difícil e onde o acaso pode desempenhar um importante papel: deixar um tecido cair de qualquer maneira sobre uma superfície, usá-lo em viés (tecido em diagonal), testar amassamentos, cortes ou dobragens inusitadas, são técnicas onde o diálogo com o imprevisível é uma constante e, para o qual, o desenho tem limitações para dar conta, mas que podem ser elementos diferenciadores em um processo criativo em design de vestuário.

Entretanto, uma vez definido o aspecto final, o modelo é planificado e transferido para moldes convencionais de modelagem plana, onde o desenho técnico volta a ter sua importância, agora para o processo de produção industrial em larga escala ou mesmo de peça única (Figura 3). Ainda assim, o fato de se poder elaborar uma vestimenta sem a criação prévia de um croqui demonstra que o desenho como parte do processo criativo pode ser dispensado. Neste caso, o desenho torna-se uma etapa posterior, que não pertence à criação da peça e sim à sua reprodução.

Figura 3: Elaboração de moldes a partir de peças provenientes da moulage.

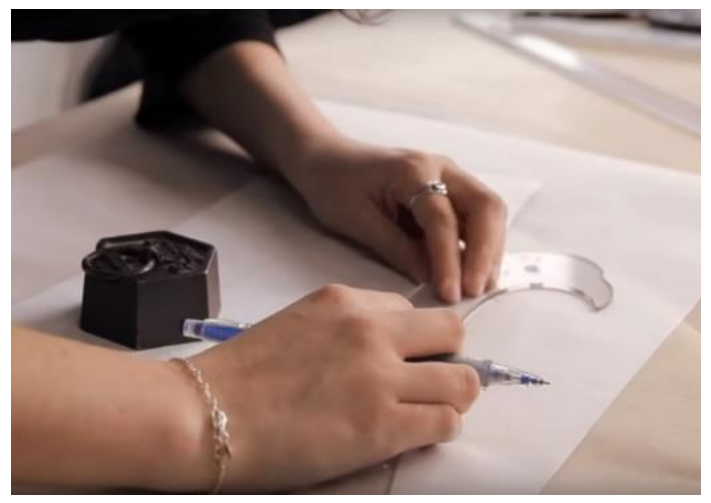

Fonte: Frame de vídeo disponível no YouTube (2020) 


\subsection{Design e cerâmica}

O processo de criação e sistema produtivo em cerâmica artesanal é muito variado, havendo profissionais que não abrem mão de um registro prévio como fio condutor de sua criação, até aqueles que têm na experimentação diretamente na argila o seu processo criativo. Levado a efeito utilizando três técnicas básicas - modelagem, torneamento e moldagem -, as peculiaridades do processo de trabalho dos profissionais farão com que o desenho tenha maior ou menor importância. Embora tenha um uso hegemônico entre ceramistas (RODRIGUES, 2011), é possível detectar profissionais que desconsideram este recurso, utilizando mais sua própria experiência no manuseio da matéria prima, adquirida ao longo do tempo e da vivência com o material, de modo a explorar seus limites, em uma situação em que o desenho não responderia adequadamente às peculiaridades de seu processo criativo/produtivo.

A ceramista Marina Freitas de Carvalho, da Alma Objetos Cerâmicos, (www.instagram.com.br/alma.objetos.ceramicos), detalha seu processo de criação de peças de tiragens variáveis: "Inicio manipulando o bloco de argila, sem ter algo desenhado. Fico atenta às formas que vão surgindo no torno, até encontrar uma que me agrade e que possa ser reproduzida posteriormente em pequenas tiragens" (CARVALHO, 2020). Uma vez definida a peça matriz, as demais são produzidas replicando-a, em um processo de fabricação por imitação. Mesmo quando produzidas em série, por meio de moldes de gesso e barbotina (argila líquida), os moldes são projetados em função da experiência da ceramista, dispensando a intermediação do desenho (Figura 4).

Figura 4: Molde de gesso para produção de peças cerâmicas padronizadas.

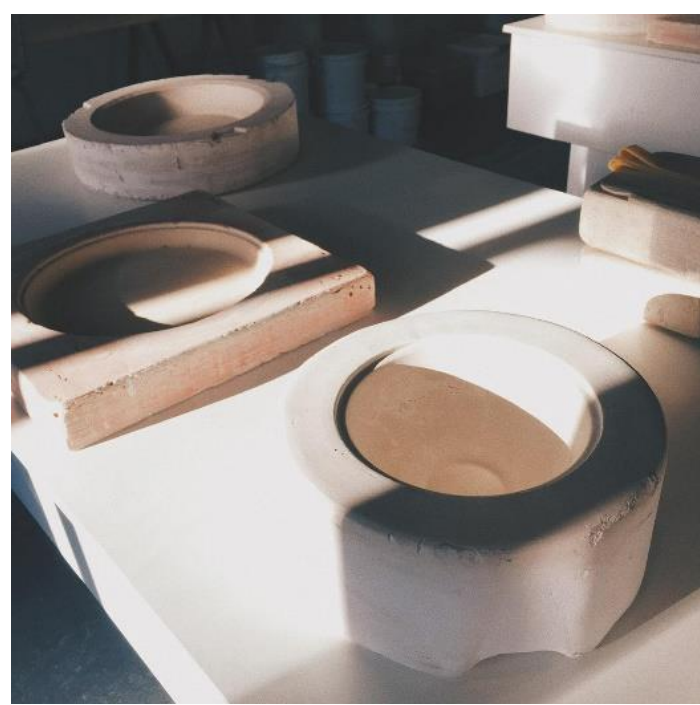

Fonte: Cortesia de Alma Objetos Cerâmicos/Marina Freitas de Carvalho, 2020. 
Quando as peças devem ter padrões formais e dimensionais semelhantes, serão os moldes que garantirão a uniformidade das peças reproduzidas a partir deles. Estes moldes, por sua vez, também podem ser elaborados diretamente no gesso, em função da experiência e conhecimento que a ceramista tem sobre o material.

\subsection{Design e artesanato}

Nas últimas décadas o artesanato brasileiro tem se beneficiado de ações de qualificação de sua produção, levadas a efeito por designers e pesquisadores da área, geralmente desenvolvidas diretamente com os artesãos em seu próprio local de trabalho e/ou moradia. Via de regra, estes artesãos têm níveis de educação formal mais elementares, onde o desenho não tem a importância como meio de comunicação que adquiriu em outros segmentos, fazendo com que o fazer artesanal seja majoritariamente baseado na transmissão oral e gestual dos saberes acumulados em anos de prática. Assim, será pela observação e imitação de algo já produzido, ou pela experimentação direta sobre os materiais, que serão criados novos objetos.

Renato Imbroisi (www.facebook.com/renato.imbroisi) é um dos pesquisadores que desenvolve um trabalho pioneiro na valorização do artesanato brasileiro contemporâneo, participando de ações incentivadoras junto a comunidades de artesãos pelo país afora e exterior há mais de 30 anos. No início de sua carreira, na década de 1980, o trabalho de Imbroisi era realizado apenas por ele em conjunto com as comunidades de artesãos, sem outros colaboradores. Nessas condições, suas ações procuravam "observar, experimentar, analisar, tirar de dentro de cada um o melhor da criatividade" (IMBROISI, 2020), e a ausência de desenhos descritivos das técnicas de manufatura não era um impeditivo para a realização de oficinas e demais atividades. Mas à medida que colaboradores de outras áreas (arquitetos, designers, artistas) passaram a integrar os diferentes projetos, contribuindo para a expansão nacional e internacional das ações, o desenho passou a fazer parte como facilitador do diálogo designers/artesãos. A comunicação entre os integrantes dos grupos de trabalho tornou-se mais fácil e objetiva, ampliando o repertório de comunicação dos artesãos, pois passaram a visualizar as peças por meio de um recurso que não lhes era familiar, mas que rapidamente foi incorporado ao seu repertório de comunicação (Figura 5). 
Figura 5: Desenho de orientação para produção de peça em palha de carnaúba, realizado pela arquiteta Lui Lo Pumo durante oficina em Santa Luzia - Jaguaruana/CE. Coordenação geral de Renato Imbroisi, 2018.

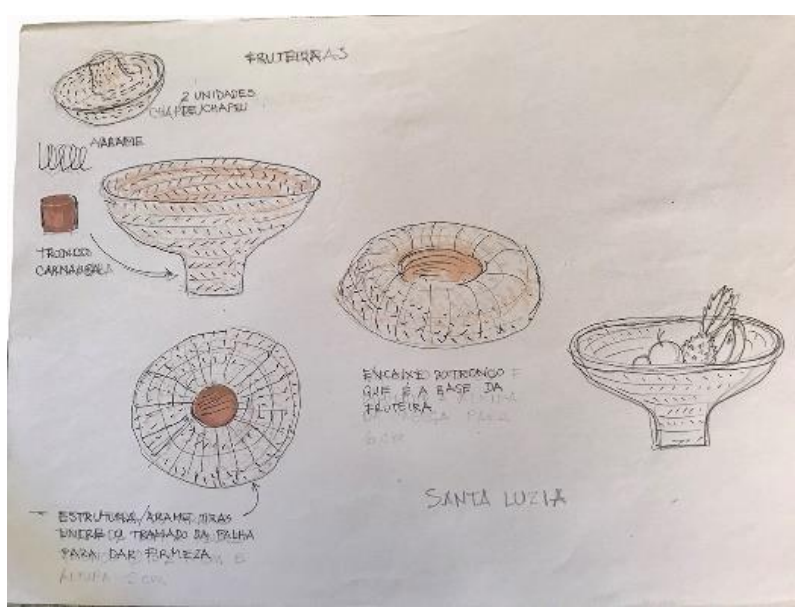

Fonte: Cortesia de Lui Lo Pumo, 2020.

Embora a produção artesanal brasileira seja muito peculiar, não contemplando etapas tradicionais preconizadas pelas metodologias de projeto, em seu livro Desenho de fibra (2011), Imbroisi e Kubrusly apresentam uma metodologia para ações em comunidades de artesãos que inclui as seguintes etapas: diagnóstico; planejamento; capacitações paralelas; oficinas de artesanato; gestão comercial; lançamento, divulgação, comercialização e; acompanhamento. Pode-se perceber nesta proposta a ausência de etapas de projeto formalizado nos moldes das metodologias consagradas, mas sim uma proposta de desenvolvimento de produtos "com muita conversa, fazendo junto, testando e transformando até chegar a um resultado interessante" (IMBROISI; KUBRUSLY, 2011, p. 30) ${ }^{3}$, quando o desenho pode ou não estar presente, mas sempre com importância relativa se comparado com a produção industrial em larga escala.

0 respeito pelo saber-fazer de comunidades de artesãos é uma caraterística marcante do trabalho de Imbroisi e de outros designers que atuam neste segmento. Levando em conta os conhecimentos acumulados por anos de prática sobre os materiais, as etapas de criação e produção podem eventualmente dispensar instâncias de antecipação intermediadas pelo desenho. Segundo Imbroisi (2020), a eventual falta do desenho neste tipo de ação não impede o diálogo e a realização do trabalho. No entanto, sua presença pode tornar os procedimentos e ações durante as oficinas mais rápidos e resolutivos, pois permite que os participantes compartilhem ideias até então

3 Uma pequena amostra do trabalho de Imbroisi em prol da valorização do artesanato pode ser vista no vídeo IBIRÁ Muquém, disponível em https://www.youtube.com/watch?v=mQrysvAyoQ4 Acesso: 07/04/2020. 
restritas à mente do idealizador, tendo o desenho como suporte, que pode ser desde um desenho técnico até um simples rabisco ou croqui da peça imaginada.

\subsection{Design de mobiliário}

Outro exemplo de relativização do papel do desenho no campo do design pode ser observado no trabalho dos irmãos Campana. Talvez os designers brasileiros de maior reconhecimento no exterior, Fernando e Humberto Campana aparentemente não têm no desenho seu recurso de projeto e produção mais significativo. Algumas evidências dessa situação podem ser apontadas: em uma busca no Google Images pelas palavras Campana + desenho (ou Campana brothers + drawing) não indicou nenhum resultado em que fossem mostrados desenhos, apenas imagens dos produtos já finalizados; o site dos designers (campanas.com.br) apresenta poucos desenhos de suas peças, geralmente de obras monumentais não realizadas; no início de sua carreira o trabalho dos irmãos chamou a atenção do editor italiano Massimo Morozzi, da marca Edra, interessando em produzir a Poltrona Vermelha, feita a partir de um rolo de corda comprado em uma feira. Ao solicitar um desenho esquemático da poltrona, o editor recebeu dos autores um vídeo onde expunham o método de entrelaçamento (AZDECOR, 2020), pois o processo de projeto baseava-se na experimentação sobre o produto e seus componentes (em uma técnica semelhante à moulage do design de moda). Darrin (2010) confirma este procedimento, afirmando que o projeto iniciou sem estudos preliminares ou desenhos, se baseando unicamente em descobertas espontâneas que aconteceram durante o processo. Pela complexidade, dificuldade de representação e caráter autoral de suas peças, o trabalho in situ com a presença dos autores e sem apoio no desenho parece ser a sistemática de projeto adotada; 4 eles próprios afirmam: "Descobrimos que não era o projeto ou a função que daria a chave para um produto, mas sim, o material e sua produção. (...) Nós nunca começamos pela forma. Aprendemos com os materiais; eles nos dizem as formas que devem tomar". ${ }^{5}$

Muitas vezes produzidos em edições limitadas, os produtos dos irmãos Campana aproximam-se da vertente que considera o design como arte. Esta condição faz com que os aspectos relativos à reprodutibilidade das peças (intermediada ou não pelo desenho, sobretudo o desenho técnico que

\footnotetext{
${ }^{4}$ Esta prática pode ser observada no projeto de uma Gloriette, 2010. Disponível em https://www.youtube.com/watch?v=iwz_2Apq-8s Acesso: 18/08/2020.

5 Conforme HO, Cathy Lang (p. 28). Something from nothing: materials and process in the work of the Campana brothers. In: Campana Brothers. Complete works (so far). New York: Rizzoli International Publications, 2010. P. 28-38. No original: "We discovered that wasn't the design or the function that would give us the key to a product, but rather the material and its production. (...) We never begin with a set form. We learn from the materials; they tell us what forms they should take." Tradução livre do autor. 0 livro não mostra desenhos das obras, apenas fotografias das peças já produzidas.
} 
acompanharia a execução) não tenha a mesma importância que em outros processos industriais (Figura 6).

Figura 6: Poltrona Vermelha, produzida sem apoio no desenho.

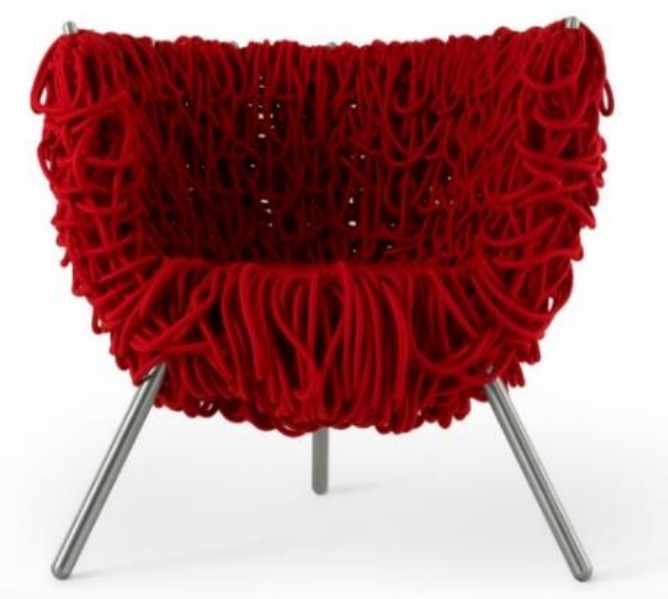

Fonte: www.campanas.com.br

Na vasta produção dos irmãos Campana é possível encontrar outros produtos onde é possível perceber que o desenho não tem uma contribuição significativa no processo de projeto/produção. É o caso da poltrona Favela (Figura 7), licenciada para a marca Edra, que utiliza tacos de madeira sobre uma estrutura sólida, em uma aparente reciclagem/reutilização de material.

Figura 7: Poltrona Favela, produzida sem apoio no desenho.

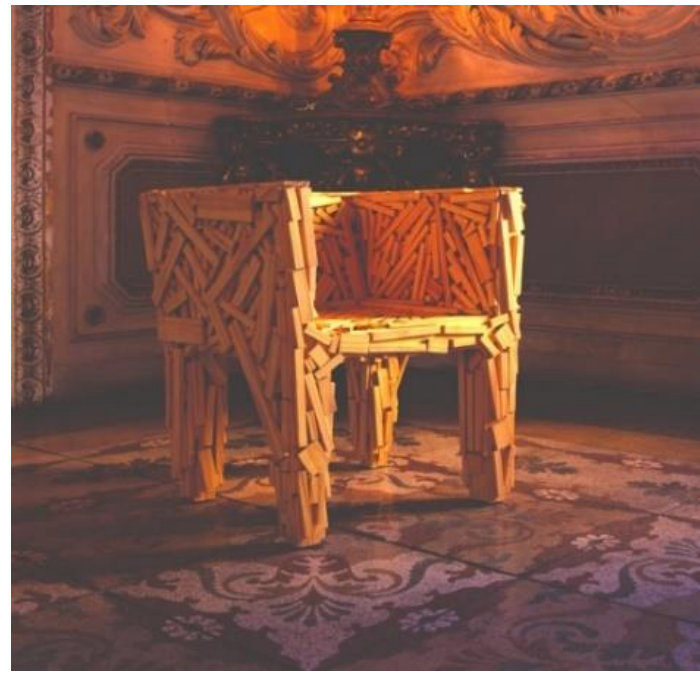

Fonte: www.campanas.com.br

Mesmo havendo fortes indícios de um aparente uso restrito do desenho em seu fazer profissional, a produção dos irmãos Campana é um bom exemplo 
da criatividade e diversidade que pode ser obtida quando a experiência profissional pode prescindir de uma ferramenta racional aparentemente indispensável em prol de técnicas de pesquisa e exploração diretamente sobre os materiais disponíveis.

\section{CONSIDERAÇÕES FINAIS}

O caráter antecipatório do desenho como mediador de processos de criação e produção sempre esteve atrelado às circunstâncias de uma época, seja sob o ponto de vista de suas próprias técnicas, seja sob o ponto de vista das características da imagem criada, respondendo às peculiaridades do momento histórico em que foi produzido. As rápidas mudanças das técnicas e recursos para projeto e visualização em 3D ocorridas nos últimos anos trouxeram inúmeros benefícios, tanto para a própria visualização facilitada quanto para os processos criativos/produtivos. Ao deixar de exigir capacidades cognitivas específicas para interpretar e visualizar objetos tridimensionais a partir de sua representação bidimensional, foi possível ampliar o acesso à interpretação de imagens técnicas relativas à produção de objetos.

Este cenário se mostraria propício para afirmar a prevalência do desenho como ferramenta ideal no contexto de processos de projeto e fabricação em design. No entanto, as especificidades de alguns processos de projeto e execução adotados por designers, projetistas e produtores tornam esta afirmação relativa. De acordo com Margolin (2002), a tecnologia permitiu que os designers criassem seus próprios nichos de mercado, trabalhando fora do modelo de indústria convencional. Para isso, os designers tornam-se também produtores, muitas vezes se aproximando do modelo de produção artesanal.

Os casos e exemplos apresentados neste artigo permitem afirmar que, embora a importância do desenho seja inquestionável na produção em design moderno, sobretudo no âmbito da produção industrial em larga escala, sua participação em determinados nichos pode ser relativizada ou reduzida. Em algumas situações específicas de processos de projeto/fabricação em algumas áreas do design, o desenho não desempenha o papel hegemônico que o caracteriza na maioria dos processos, o que, de maneira nenhuma, reduz sua importância enquanto instância de antecipação. Por outro lado, essa eventual ausência pode abrir espaço para processos criativos não intermediados pela racionalidade de alguns tipos de desenho, sobretudo os desenhos técnicos.

Os casos específicos aqui relatados mostram que, sobretudo quando a criatividade exerce grande protagonismo nas etapas que conduzem ao resultado final em design, a antecipação pelo desenho pode ser substituída 
pela experimentação sobre os materiais e sobre o objeto concreto, como forma de encontrar alternativas inusitadas e seus consequentes processos de produção, deixando o registro gráfico para etapas posteriores. No caso de objetos únicos e não replicáveis, igualmente o desenho também pode ter sua importância relativizada, embora nunca totalmente descartada. Essas e outras evidências indicam que em alguns processos de design, o desenho nem sempre exerce um protagonismo hegemônico - o que em nada diminui sua importância - mas em situações muito específicas, sobretudo em processos onde a experimentação sobre o próprio objeto ou material é uma alternativa para a busca de soluções criativas e inovadoras.

\section{REFERÊNCIAS}

AZDECOR. I de irmãos Campana. Disponível em www.azdecor.com.br/2014/09/i-de-irmaos-campana/ Acesso em 15 mar. 2020.

BÜRDEK, Bernhard. História, Teoria e Prática do Design de Produto. São Paulo: Ed. Edgard Blücher, 2006.

Campana Brothers. Complete works (so far). New York: Rizzoli International Publications, 2010.

CARVALHO, Marina Freitas de. Entrevista ao autor. Porto Alegre, 30 mar. 2020. 20'

CATTANI, Airton. Aspectos históricos do desenho de design. In: OLIVEIRA, Geisa Gaiger de; NÚÑEZ, Gustavo Javier Zani. Design em Pesquisa - Volume 3. Porto Alegre: Marca Visual, 2020, p. 601-615.

CATTANI, Airton; LEENHARDT, Jacques. Taxonomia da representação em design. In: Revista Educação Gráfica, v. 21, p. 270-282, 2017.

DARRIN, Alfred. Displaced Materials. In: Campana Brothers. Complete works (so far). New York: Rizzoli International Publications, 2010. p. 128-142.

DONDIS, Dondis. Sintaxe da Linguagem Visual. São Paulo: Martins Fontes, 2007.

FERRO, Sérgio. 0 canteiro e o desenho. São Paulo: Projeto, 1982.

FRUTIGER, Adrian. Sinais e símbolos - desenho, projeto e significado. São Paulo: Martins Fontes, 1999. 
IMBROISI, Renato; KUBRUSLY, Maria Emilia. Desenho de fibra: artesanato têxtil no Brasil. Rio de Janeiro: Senac Nacional, 2011.

IMBROISI, Renato. Entrevista ao autor. Porto Alegre, 08 abr. 2020. 22 50"

JUNGMANN, Jean-Paul. L'image en achitecture: de la représentation et de son empreinte utopique. Paris: Éditions de la Villette, 1996.

MARGOLIN, Victor. The Designer as Producer. Disponível em: https://readings.design/PDF/designer_as_producer.pdf. Acesso em 08 jul. 2020.

MIDAL, Alexandra. Design. Introduction à l'histoire d'une discipline. Paris: Agora, 2009.

MUNARI, Bruno. Design as art [Arte comme mestieri]. Middlesex: Penguin Books, 1971.

RODRIGUES, Maria Regina. Cerâmica. Vitória: UFES, 2011.

SAINT-AUBIN, Jean-Paul. Une histoire du relevé. In: SAKAROVITCH, Joël. Mesures et grands chantiers. 4000 ans d'histoire. Paris: Ordre des Géometres-Experts, 2002.

\section{Agradecimentos}

Os autores agradecem a colaboração de Marina Freitas de Carvalho, Lui Lo Pumo e Renato Imbroisi pelas informações relativas a seus trabalhos. 